\title{
Assessment of dual-polarized interference due to precipitation for high-capacity satellite communication systems in Nigeria
}

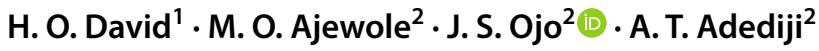

Received: 27 November 2019 / Accepted: 22 July 2020 / Published online: 30 July 2020

(c) Springer Nature Switzerland AG 2020

\begin{abstract}
High-capacity satellite systems are specially designed to provide several gigahertz-allotted spectra for multiple spot beams. The reliability of the communication links at high frequencies is often subjected to rain attenuation. In addition to rain attenuation, rain-induced cross-polarization is an important factor for dual-polarization microwave radio communication systems operating at such frequencies. Dual-polarized communication systems adopting frequency reuse usually encounter interference due to a change of transmission energy from one polarization state to another. Signal degradation as a result of some degree of noise causes reduction in the quality of signal between the two orthogonal channels-cross-polarization discrimination (XPD). Therefore, this study assesses the level of degradation due to interference on dual-polarized communication systems for millimeter wave's band over some selected locations in Nigeria using 5 years (2008-2012) data collected at tropical data acquisition network of the Centre for Atmospheric Research Anyigba. Assessment of dual-polarized interference is based on cumulative distribution of XPD at different frequencies, effect of Earth station receiver frequencies on XPD, XPD-CPA (Co-polar attenuation) relationship and XPD-rain rate relations. Influence of polarization tilt angle for linear and circular polarization on XPD was also assessed. The specific result shows that XPD is extremely low at high rain rates for frequency up to $20 \mathrm{GHz}$. Depolarization effect is better at the lowest availability with higher value of XPD, and its performance contributes to system availability at the low exceedance probabilities. Port Harcourt, Nsukka, Yola and Sokoto experiences increased interference at receiver stations than other locations considered in this study, especially at Q/V band frequencies. Additional fade margin and appropriate mitigation methods for link availability and good quality of service will be required for sustainability.
\end{abstract}

Keywords Dual-polarized systems · Interference $\cdot$ Precipitation $\cdot$ High-capacity satellite $\cdot$ Tropical region

\section{Introduction}

As urges for information technology grow globally, so also is the urge for high-volume, high-data rate satellite-toground communications. Signal transmission at frequencies above $10 \mathrm{GHz}$ is restricted by various meteorological conditions which impose severe limitations on radio systems operating in the millimeter region of the spectrum $[1-3]$. The characteristics of signal transmission through the space can be significantly influenced by the atmosphere. As the frequency of propagation increases, so is the information to be transmitted. When rain falls along the path of propagation systems, especially those operating at frequencies higher than $10 \mathrm{GHz}$, signal degradation occurs which may cause a reduction in the quality of signal at the receiver. The scenario in the tropical (e.g., Nigeria) and subtropical (e.g., South Africa) is a bit peculiar in terms of attenuation and depolarization due to the

$\triangle$ J.S. Ojo, ojojs_74@futa.edu.ng; H. O. David, dherryolatunji@yahoo.com; M. O. Ajewole, oludare.ajewole@futa.edu.ng; A. T. Adediji, kunleadediji2002@yahoo.co.uk | ${ }^{1}$ Department of Science Lab Technology, Offa Polytechnic, Offa, Kwara State, Nigeria. ${ }^{2}$ Department of Physics, Federal University of Technology Akure, Akure, Nigeria. 
relatively high occurrence of heavy rainfall with the large size of rain drops and high rain intensity [4]. These have led to considerable interest in the subject theoretically and experimentally [4-10] among others. The technique of dual polarization based on the transmission from another channel of a polarization orthogonal to the first effectively doubles the usable frequency spectrum. This among other factors has led to a phenomenon termed frequency reuse techniques. The frequency reuse technique is usually employed to expand the communication system channel; thus, increase in order of magnitude can be achieved. The channels can be divided into smaller ones and which are used repeatedly to send signals into another location of considerable distances. The smaller unit of the channel is termed co-channel, while the energy that may leak out of the channel is termed co-channel interference. Any system adopting the dual-orthogonal polarization is prone to such interference and invariably reduces the output performance of such systems. Despite the propagation problems, encounter with frequency reuse scheme using millimeter and microwave frequencies, it was found to be highly valuable for telecommunication services, especially for long-distance links because of the fairly good bandwidth.

Attenuation along the propagation channel of the transmitter and the crosstalk within the channel of the receiver are the two major ways by which the dual-polarized communication links are affected by precipitation. The extent of the signals degradation can be determined through the use of cross-polarization isolation (XPI) which is the ratio of the wanted signal level to the unwanted signal level in the same receiver channel when two polarizations are transmitted simultaneously [6]. Cross-polarization discrimination (XPD) is sometimes used in place of XPI because it is essentially related for all practical purposes. XPD is the ratio of the received signal in the same (copolarized) state as the transmitted wave to the received signal in the cross-polarized state for a single transmitter polarization. Hence, this paper addresses depolarization in terms of XPD because we only dealt with the degree of the interference between the two orthogonally polarized channels. In addition, XPD is an important characteristic, particularly in dual-polarized systems, where crosstalk between polarizations can prevent the system objectives from being achieved (slow speed, wasted spectrum, unhappy customer, etc.).

The relationship between co-polar attenuation and cross-polarization has been identified to have an influence of variation in climatic and geographical factors [11]. Extensive studies are therefore needed to have better knowledge and reliable modeling of propagation impairments in the tropical region, particularly in Nigeria where there is varying rain and inadequate transmission data. Hence, this study is to further assess the impact of dual polarization on highcapacity satellite communication systems in Nigeria. This will assist in the design of efficient and reliable communication systems in the country.

The rest of the paper is organized as follows: Sect. 2 gives a brief background on depolarization due to hydrometeor while a methodology adopted using different methods of estimating XPD because rain is presented in Sect. 3. The results of simulating XPD due to rain are discussed in Section 4. Finally, Sect. 5 presents the concluding remarks.

\section{Depolarization due to rain}

There are several parameters that influence depolarization due to rain on the communication link systems, among are the frequency of the link and the elevation angle along the path in degrees. Others are the polarization tilt angle of the linearly polarized electric field vector, which describes its orientation with reference to the local horizontal height of the Earth-station, and the co-polar rain attenuation (dB) that occurs concurrently due to the same rain event.

According to Karasuwa et al. [9], polarization angle ( $\tau$ ) among other factors determines the level of depolarization. The polarization angle is defined with reference to the Earth station as:

$\tau=90^{\circ}-\tan ^{-1}\left(\frac{\tan \left(L_{\mathrm{e}}\right)}{\sin \left(I_{\mathrm{s}}-I_{\mathrm{e}}\right)}\right)$

where $L_{\mathrm{e}}$ is the earth station latitude, $I_{\mathrm{e}}$ is the earth station longitude and $I_{s}$ is the subsatellite point longitude.

As earlier stated in section one that in dual-polarized satellite communication systems, the XPI level measures the extent of the level of interference between the co-channels and XPD is the representation of the XPI for all practical purposes. Hence, the XPD for linearly polarized waves, for both vertical $\left(E_{1}\right)$ and horizontal $\left(E_{2}\right)$ directions, is defined by $[2,9]$ :

$\mathrm{XPD}_{(1,2)}=20 \log _{10}\left(\frac{E_{11,22}}{E_{12,21}}\right)$

where $E_{11,22}$ are the co-polar received electric field vectors and $E_{12,21}$ are the corresponding cross-polar received vectors.

\section{Methodology and modeling}

Five years (2008-2012) of rain rate data were used for this study and were collected from the Tropospheric Observatory Data Acquisition Network (TRODAN) of the Centre for Atmospheric Research of NASRDA, Kogi State University, Anyigba, Nigeria, spread across ten selected locations in 
Nigeria. The selected locations are: Akure $\left(7.17^{\circ} \mathrm{N}, 5.18^{\circ} \mathrm{E}\right)$, Akungba $\left(7.52^{\circ} \mathrm{N}, 5.77^{\circ} \mathrm{E}\right)$, Anyigba $\left(7.48^{\circ} \mathrm{N}, 7.18^{\circ} \mathrm{E}\right)$, Lagos $\left(6.30^{\circ} \mathrm{N}, 3.20^{\circ} \mathrm{E}\right)$, Makurdi $\left(7.32^{\circ} \mathrm{N}, 8.53^{\circ} \mathrm{E}\right)$, Nsukka $\left(6.52^{\circ} \mathrm{N}\right.$, $\left.7.24^{\circ} \mathrm{E}\right)$, Jos $\left(8.50^{\circ} \mathrm{N}, 9.50^{\circ} \mathrm{E}\right)$, Yola $\left(9.20^{\circ} \mathrm{N}, 12.48^{\circ} \mathrm{E}\right)$, Port Harcourt $\left(4.20^{\circ} \mathrm{N}, 7.00^{\circ} \mathrm{E}\right)$ and Sokoto $\left(5.13^{\circ} \mathrm{N}, 13.04^{\circ} \mathrm{E}\right)$. The data obtained from these locations were used to deduce the level of depolarization due to rain. The characteristics of the locations are presented in Table 1. Each of the experimental sites is equipped with the Campbell Automatic Weather Station (AWS) to measure total rain accumulation and rain rate among the measurements. The equipment consists of sensors for the measurement of climatological parameters such as rain, atmospheric pressure, air temperature, soil temperature, relative humidity, wind speed and wind direction among others. Rain depolarization (Cross-Polarization Discrimination-XPD) is computed for frequencies between $\mathrm{Ku}(12 / 18 \mathrm{GHz})$ and Q/V $(40 / 55 \mathrm{GHz})$ bands for each location using the data acquired based on ITU-R 618-12, (2015) model for rain rate, polarization, elevation angles and canting angles. The model has been adjudged as the most acceptable internationally for prediction of propagation impairments $[12,13]$.

The step by step method of estimating XPD for $6 \leq f \leq 55 \mathrm{GHz}$ at $\theta \leq 60^{\circ}$ based on ITU-R 618-12 [14] are as follows:

The frequency-dependent term was calculated using:

$$
C_{f}=\left\{\begin{array}{ll}
60 \log f-28.3 & 6 \leq f \angle 9 \mathrm{GHz} \\
26 \log f+4.1 & 9 \leq f \angle 36 \mathrm{GHz} \\
35.9 \log f-11.3 & 36 \leq f \leq 55 \mathrm{GHz}
\end{array}\right\}
$$

where $f$ is the frequency in $\mathrm{GHz}$.

The rain attenuation-dependent terms, $C_{A}$, were also calculated using:

$C_{\mathrm{A}}=V(f) \log A_{P}$ where $A_{p}$ is the estimated rainfall attenuation (in $\mathrm{dB}$ ) exceeded for the required percentages of time and $V(f)$ is given as:

$$
V(f)=\left\{\begin{array}{ll}
30.8 f^{-0.21} & 6 \leq f \angle 9 \mathrm{GHz} \\
12.8 f^{0.19} & 9 \leq f \angle 20 \mathrm{GHz} \\
22.6 & 20 \leq f \angle 40 \mathrm{GHz} \\
13.0 f^{0.15} & 40 \leq f \leq 55 \mathrm{GHz}
\end{array}\right\}
$$

The polarization improvement factor $C_{\tau}$ for the depolarization is obtained using:

$C_{\tau}=-10 \log [1-0.484(1+\cos 4 \tau)]$

where $C_{\tau}=0$ for $\tau=45^{\circ}$ for circular polarization and reaches the maximum value of $15 \mathrm{~dB}$ for $\tau=0^{\circ}$ or $90^{\circ}$.

The elevation angle-dependent term for $\theta \leq 60^{\circ}$ was obtained using:

$C_{\theta}=-40 \log (\cos \theta)$

while the canting angle-dependent term was derived from:

$C_{\sigma}=0.0053 \sigma^{2}$

where $\sigma$ is the effective standard deviation of the raindrop canting angle distribution (in degrees). $\sigma$ takes the value $0^{\circ}, 5^{\circ}, 10^{\circ}$ and $15^{\circ}$ for $1 \%, 0.1 \%, 0.01 \%$ and $0.001 \%$ of the time, respectively. For this study, $\sigma$ was taken as $10^{\circ}$.

The XPD due to rain $\left(X P D_{\text {rain }}\right)$ was therefore obtained using:

$\mathrm{XPD}_{\text {rain }}=C_{f}-C_{A}+C_{\tau}+C_{\theta}+C_{\sigma}(\mathrm{dB})$

This model permits the evaluation of the cumulative distribution function of cross-polar discrimination by means of an equiprobable relationship between the attenuation and the XPD.

The estimated attenuation to be exceeded for other percentages of an average year, in the range $0.001-5 \%$,
Table 1 Characteristics of the research sites

\begin{tabular}{lccccl}
\hline Location & Latitude $\left({ }^{\circ} \mathrm{N}\right)$ & Longitude $\left({ }^{\circ} \mathrm{E}\right)$ & Altitude $(\mathrm{m})$ & $\begin{array}{l}\text { Annual Mean } \\
\text { Rainfall }(\mathrm{mm})\end{array}$ & Climatic region \\
\hline Akure & 7.17 & 5.18 & 358 & 1486 & Tropical rain forest \\
Akungba & 7.47 & 5.74 & 373 & 1500 & Tropical rain forest \\
Lagos & 6.52 & 3.37 & 129 & 1425 & Mangrove rain forest \\
Port Harcourt & 4.85 & 7.05 & 80 & 2803 & Mangrove rain forest \\
Anyigba & 7.49 & 7.17 & 420 & 1250 & Tropical Savannah \\
Nsukka & 6.84 & 7.37 & 103 & 1140 & Tropical savannah \\
Makurdi & 7.73 & 8.54 & 630 & 1337 & Tropical savannah \\
Jos & 8.89 & 8.85 & 1400 & 1187 & Tropical savannah \\
Sokoto & 13.00 & 5.25 & 500 & 567 & Sudan Savannah \\
Yola & 9.20 & 12.48 & 207 & 1027 & Sudan Savannah \\
\hline
\end{tabular}


is determined from the attenuation to be exceeded for $0.01 \%$ for an average year: effect is recorded in Jos. This might be due to thunderstorm rain at these locations, large size raindrops and

If $p \geq 1 \%$ or $|\varphi| \geq 36^{\circ}$ :

$\beta=0$

If $p<1 \%$ and $|\varphi|<36^{\circ}$ and $\theta \geq 25^{\circ}: \quad \beta=-0.005(|\varphi|-36)$

Otherwise: $\quad \beta=-0.005(|\varphi|-36)+1.8-4.25 \sin \theta$

$$
\begin{aligned}
A_{p} & =A_{0.01}\left(\frac{p}{0.01}\right)^{-Y} \mathrm{~dB} \\
Y & =0.655+0.033 \ln (P)-0.045 \ln \left(A_{0.001}\right)-\beta(1-p) \sin \theta \\
A_{0.01} & =\gamma L_{\mathrm{E}}
\end{aligned}
$$

$\gamma$ Specific attenuation and $L_{E}$ effective path length, $\varphi$ is the latitude of earth station.

\section{Results and discussion}

In this section, the results of analysis of rain-related depolarization interference and rain-induced attenuation on the satellite communication links in the region where the data was taken are discussed. XPD and CPA are computed for both linear and circular polarization over a varying propagation path at an elevation angle ranging from $10^{\circ}$ to $60^{\circ}$ and frequency range of $10-55 \mathrm{GHz}$ based on rain rate ranging from 5 to $210 \mathrm{~mm} / \mathrm{h}$. Other losses affecting communication system links are not considered and will be assumed to be constant for a given system in this study.

\subsection{Cumulative distribution of XPD at different frequencies}

Figure 1a-d presents the cumulative distribution of XPD at 12,20 and $40 \mathrm{GHz}$ frequencies, respectively, representing $\mathrm{Ku}, \mathrm{Ka}$ and $\mathrm{Q} / \mathrm{V}$ bands. Generally speaking, XPD improves with the increase in probability of exceedance and frequencies at all the locations of study. For example, Fig. 1a presents XPD distribution at $12 \mathrm{GHz}$ frequency (Kuband) occurring at different percentage of time, over the selected locations. It can be observed that in the worst case $(p=0.001 \%)$, XPD values are in the negative range of about $-8.0 \mathrm{~dB}$ and $-5.0 \mathrm{~dB}$ for Sokoto, Yola (Sudan Savannah region) and Nsukka, whereas higher values of about $10.0 \mathrm{~dB}$ are recorded in locations like Akure, Akungba and Lagos, which belongs to the tropical region part of the country, although the scenario is more intense at Lagos being a semi-coastal region and $\mathrm{PH}$, a coastal region. At Ka frequency band (Fig. 1b) and as percentage of time increases, rain-related depolarization interference effect improves favorably, but Port-Harcourt (Coastal region) was severely affected while a reduction in XPD interference high rainfall intensity. The particles from the frequent gas flaring often add to raindrop sizes in Port-Harcourt. PortHarcourt is located in a coastal region with very high rainfall and consequently experienced the high depolarization interference effect [3]. A similar trend of XPD at Ka bands also occurred in all the locations at Q/V frequency bands though with different values of XPD as presented in Fig. 1c.

\subsection{Effect of earth station receiver frequencies on XPD at specific percentage of exceedance}

The dependence of different earth station receiver frequencies on XPD-induced interference as a function $p$ ( 1 and $0.1 \%, 0.01$ and $0.001 \%$ ) is presented in Fig. 2a and $b$, respectively. For higher exceedances, $p=1$ and $0.1 \%$ (Fig. 2a), the results show that crosstalk initially decreases in value up to about $30 \mathrm{GHz}$ and rises slightly before retaining steady values after $40 \mathrm{GHz}$. Higher values of XPD imply low crosstalk and lower interference between channels at the earth station receiver end. The distribution of XPD in all the locations is similar as percentage of time increases. This behavioral trend of XPD-induced interference might be due to the dielectric property of water which is a frequency dependent factor and the influence of absorption coefficient of water. The dielectric constant of water initially increases with increase in frequency and attaining a threshold frequency inducing a steady fall as frequency increases. As frequency increases, attenuation also initially increases and after a threshold frequency, it tends to decrease. When the absorption coefficient of water is increased, thus leading to high attenuation and consequently leading to decrease in XPD $[3,7,15]$ in related studies observed same trend with more absorption expected at frequency of $22.3 \mathrm{GHz}$ which is the first absorption line of water vapor.

Figure $2 \mathrm{~b}$ presents for lower exceedances, $p=0.01$ and $0.001 \%$ at different earth station frequencies, lower value of XPD which implies high crosstalk and higher interference between channels at the receiver were observed when compared to the XPD values in Fig. 2a. A 3-dB difference is observed with respect to XPD at $p=0.01$ and $0.001 \%$. However, the difference between XPD becomes more obvious with increasing $p$ at Port-Harcourt, a coastal location while Jos is the most favorable. In terms of the variation in XPD-induced interference with earth station 

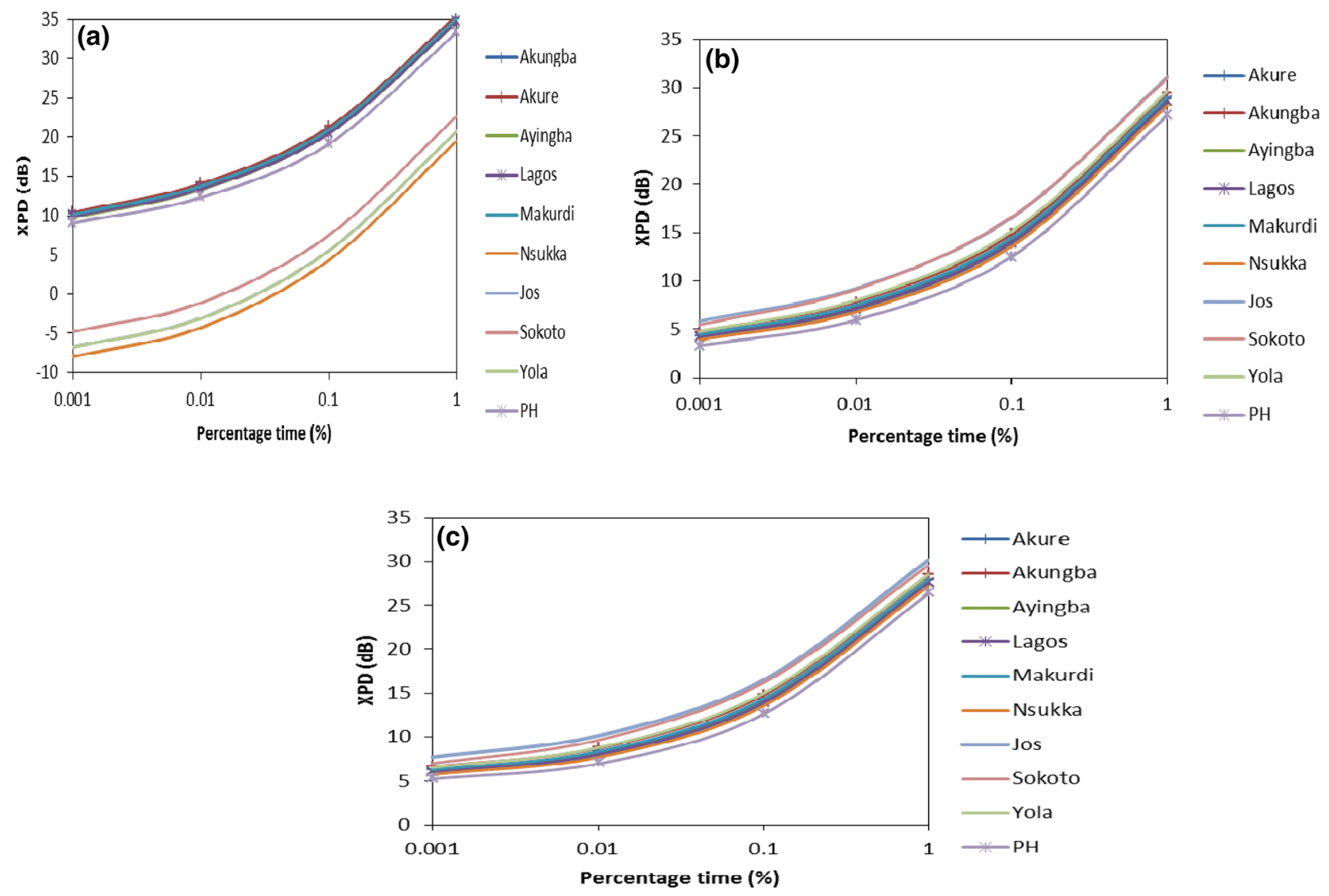

Fig. 1 Cumulative distribution of XPD at a 12, b 20 and c $40 \mathrm{GHz}$ frequencies
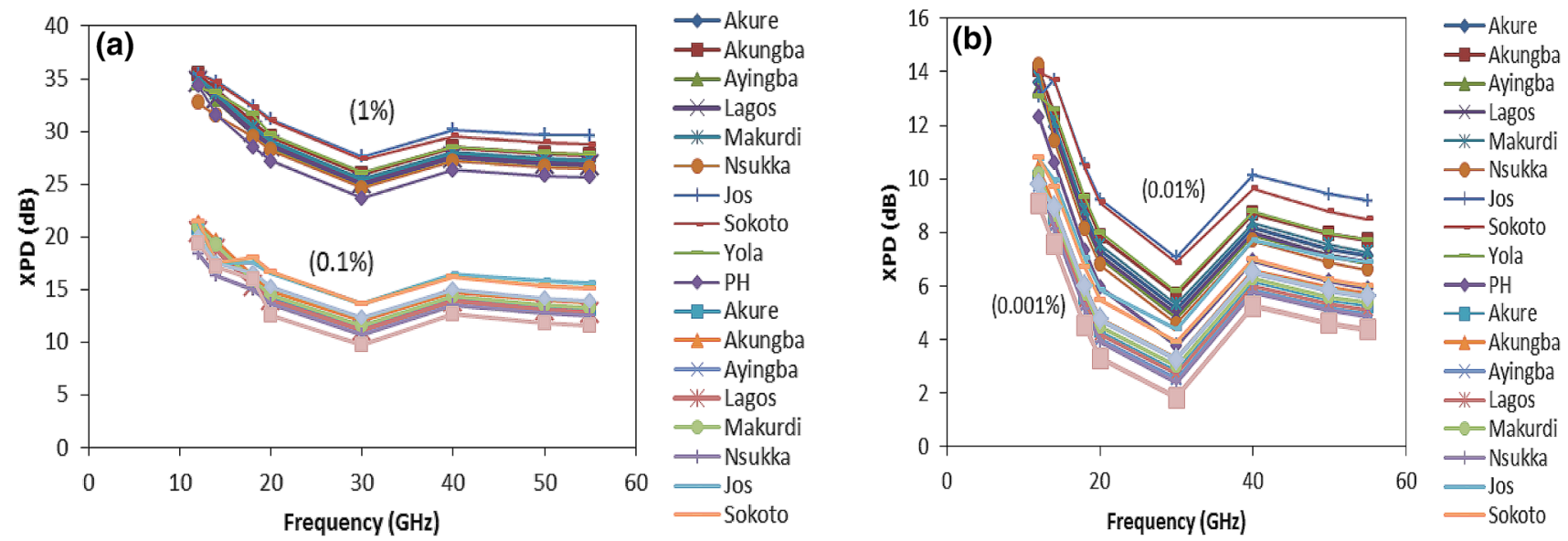

Fig. 2 Influence of Earth station frequencies on XPD at a $0.1 \%$ and $1 \%$ b $0.01 \%$ and $0.001 \%$

frequency, XPD values degrade by $1 \mathrm{~dB}$ from 12 to $55 \mathrm{GHz}$. The distribution of XPD in all the locations is similar as percentage of time increases. It is therefore evident that the depolarization effect is better at low availability with higher value of XPD and its performance contributes to system availability at the low $p$.

\subsection{XPD-CPA relationships}

Figures 3a-d show the XPD-CPA relations at $\mathrm{Ku}, \mathrm{Ka}, \mathrm{Q}$ and $V$ bands, respectively, for all the locations. XPD-CPA has earlier been identified by Van de Kamp [16] and Paraboni et al. [17] as the usual available parameter in 
communication systems design. Generally speaking, as CPA is high, XPD is low, resulting to large crosstalk. The trend indicated an inverse variation in XPD with CPA. Lower XPD implies higher interference at the receiver which implies that more crosstalk occurs, thus resulting in production of large unwanted signals at the receiving end. At Ku downlink frequency band for example (Fig. 3a), Nsukka, Yola, Sokoto and Jos experienced low XPD as CPA increases which means higher interference in these locations.

Nsukka in the tropical savannah region, southern part of Nigeria, experiences considerable amount rain rate recorded low XPD and high attenuation as absorption of signal is pronounced. The presence of large amounts of rain drop sizes resulted in high attenuation indicating high interference at receiver between the two orthogonal channels and consequently, more crosstalk. The other three locations (Yola, Sokoto and Jos) are in the northern region (savannah region) where rain rate and its occurrence are less when compared to the coastal
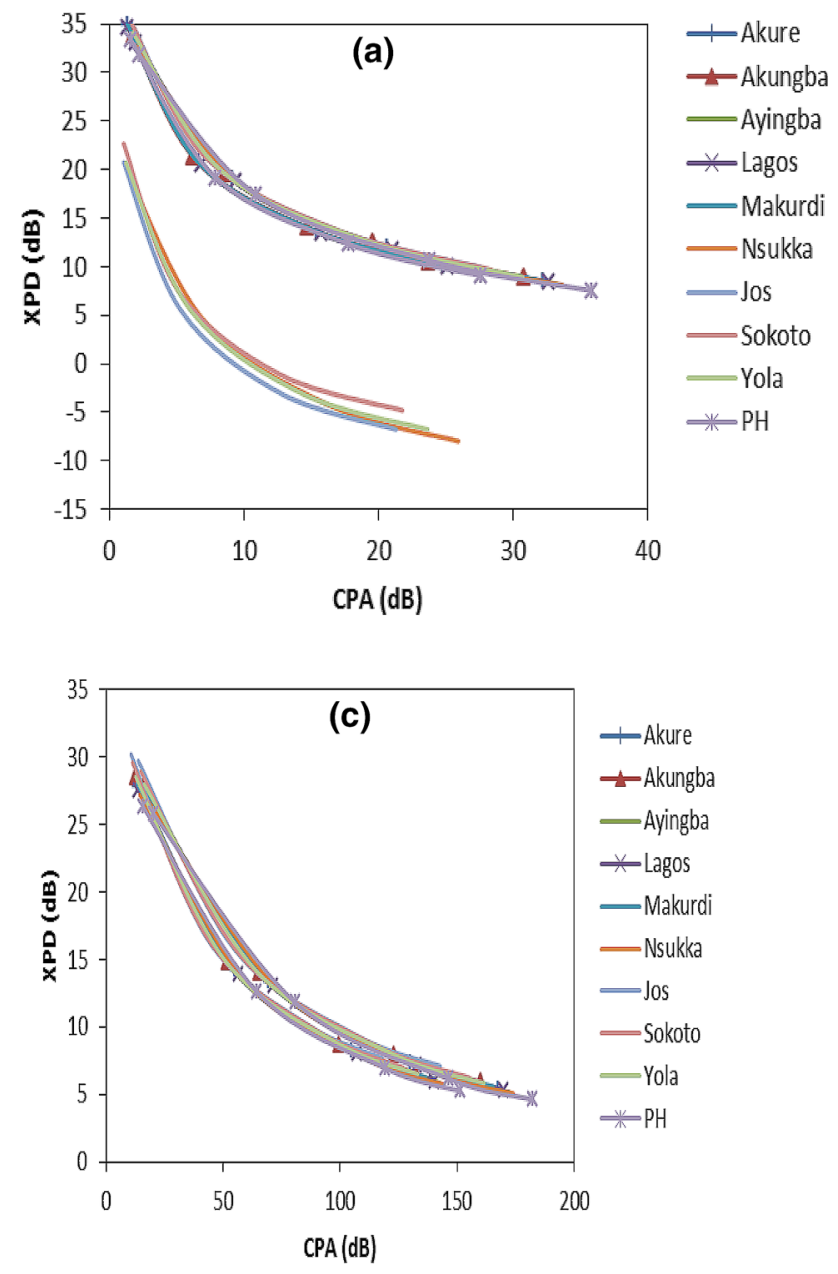

region. These locations (Yola, Sokoto and Jos) also experienced severe interference. Study revealed that in a dust storm environment, microwaves and millimeter waves passing through the precipitation (rain, dust and snow) experienced signal loss by absorption and scattering of the radio waves [18].

At Ku uplink frequency band, XPD improves better than at the downlink frequency band which means signal transmission would be better as crosstalk will be lower than at Ku downlink frequency bands at all the locations. Similar tread follows at Ka-band, but with high XPD values as presented in Fig. 3b.

At $\mathrm{Q}$ and $\mathrm{V}$ band (Fig. 3c-d), CPA is extended beyond $100 \mathrm{~dB}$, Port Harcourt, Nsukka, Yola and Sokoto still experiences increased interference at receiver stations than other locations. It must be noted that at $\mathrm{Q}$ and $\mathrm{V}$ frequency bands, degradation in signal purity in wanted polarization and signal outages in these locations will be due more to signal attenuation on the propagation link than to crosstalk in the frequency reuse systems. This observation will
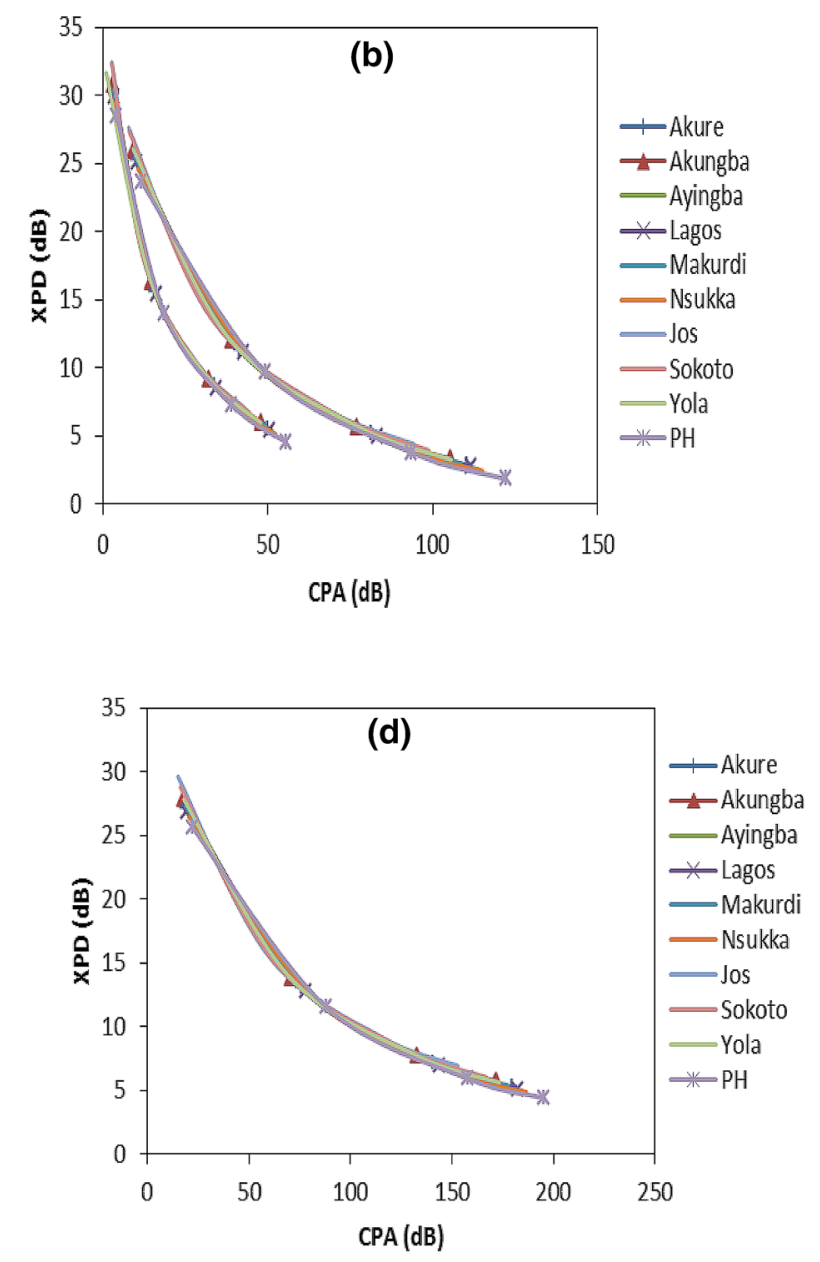

Fig. 3 XPD-CPA relationship for $\mathbf{a}$ Ku band $\mathbf{b}$ Ka band $\mathbf{c} \mathrm{Q}$ band and $\mathbf{d}$ V-band downlink frequency 
be a useful parameter for locating repeater stations for line-of-sight communication link in these locations.

\subsection{XPD-rain rate relationships}

Figures $4 a-d$ show the influence of rain rate on XPD at Ku, $K a, Q$ and $V$ frequency bands for all the locations. General speaking, as the rain rate increases orthogonal signals from different sources tend to experience more interference on reaching the receiving antenna thereby leading to higher crosstalk and reduction in XPD. This finding is in agreement with Chu $[19,20]$ and Ojo [7]. As the rain is shifting from stratiform to convective rain type (i.e., from rain rate of above $50 \mathrm{~mm} / \mathrm{h}$ to high rain rate), there is a sharp decrease in XPD leading to the more cross-polar signal coupling to the orthogonal channel at the same frequency
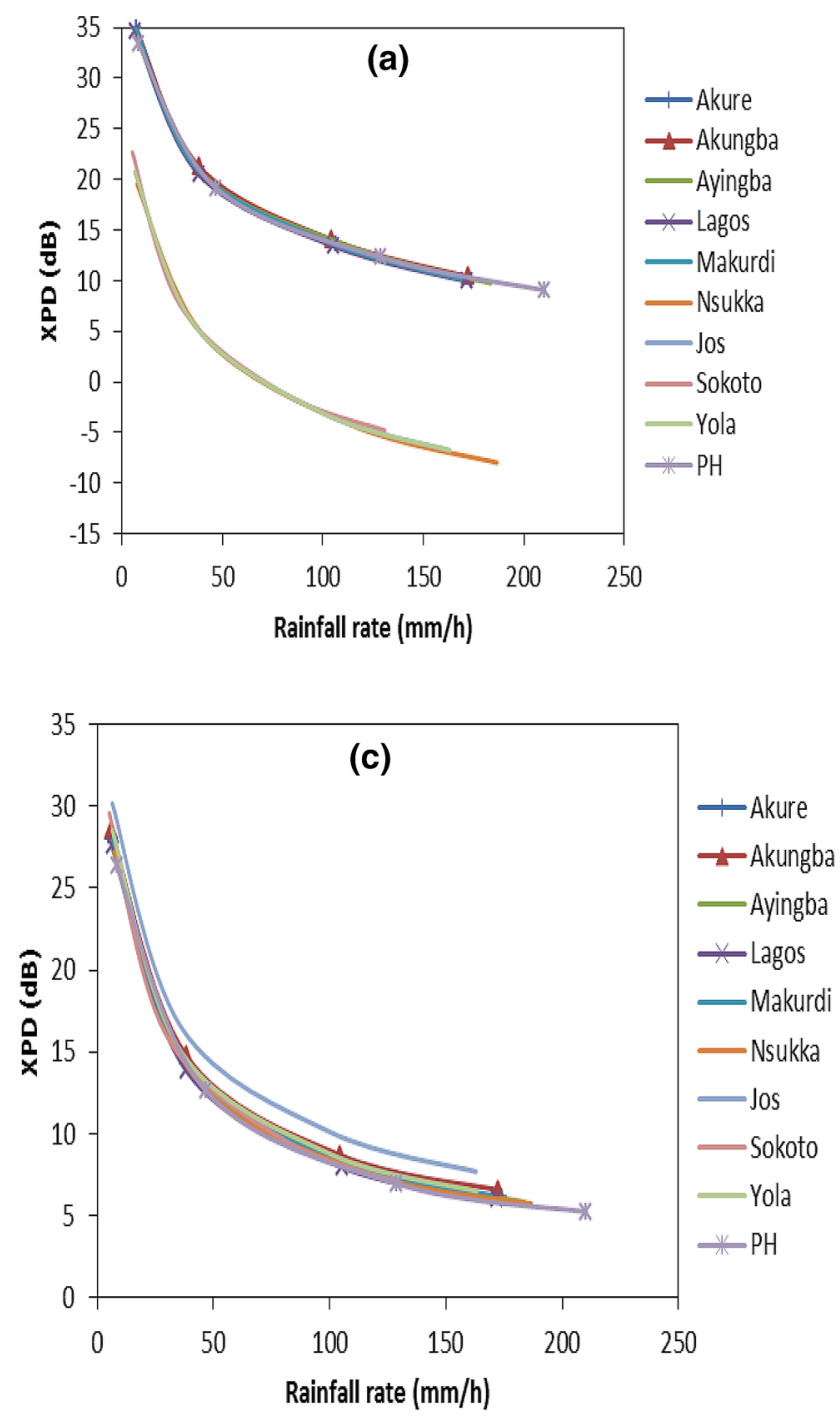

(Fig. 4a-d). Figure 4a-d further reveals that Port Harcourt, Nsukka, Sokoto, and Yola will be vulnerable to higher crosstalk than in other locations at the same frequency. As presented in Fig. $4 c-d$, there is a marginal difference in the crosstalk effects experienced in all the locations at $\mathrm{Q}$ and $\mathrm{V}$ bands. Jos has the highest XPD among all the locations implies lowest interference effect; this might be due to its lower rain fall rate compared with other stations. Consequently, it has been shown so far that depolarization is a performance-limiting factor as its impact may lead to system outage if the effects of crosstalk keep on increasing, especially at low percentages of time and if the effect on the antenna is coupled with these findings [9]. A system like direct-to-home (DTH) service may require an increase in fade margin or other mitigation methods if link availability and the quality of service (QoS) are to be sustained.
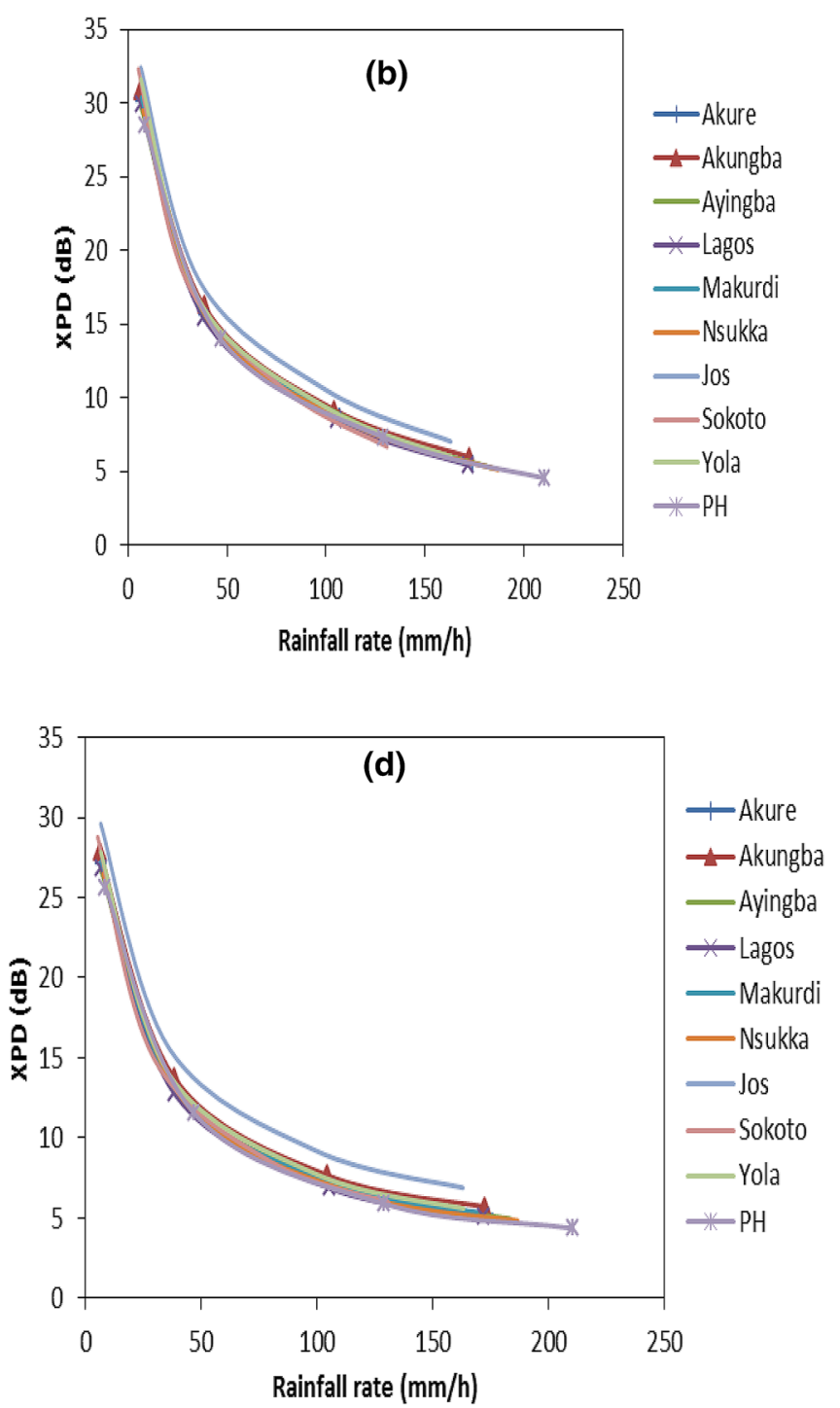

Fig. 4 XPD-rain rate relationship for $\mathbf{a}$ Ku band $\mathbf{b}$ Ka band $\mathbf{c} \mathrm{Q}$ band and $\mathbf{d} \mathrm{V}$-band downlink frequency 


\subsection{Influence of polarization tilt angle for linear polarization on XPD at $90^{\circ}$}

The influence of XPD at various elevation angles is considered in the selected frequency bands at a fixed polarization tilt angle of $45^{\circ}$ and $90^{\circ}$ based on the locations' climate. The typical results at Ku downlink and uplink and at Q/V downlink and uplink frequencies are presented for Port Harcourt, Nsukka, Sokoto and Yola, which have been identified more vulnerable to higher crosstalk than other locations at the same frequency.

At a fixed polarization tilt angle of $90^{\circ}$, for the specified locations as presented in Fig. 5, XPD shows significant improvement at Ku-downlink frequency band than at its uplink. XPD values keep on increasing as the percentage of time and elevation angle increases. In Fig. 5a, for example,
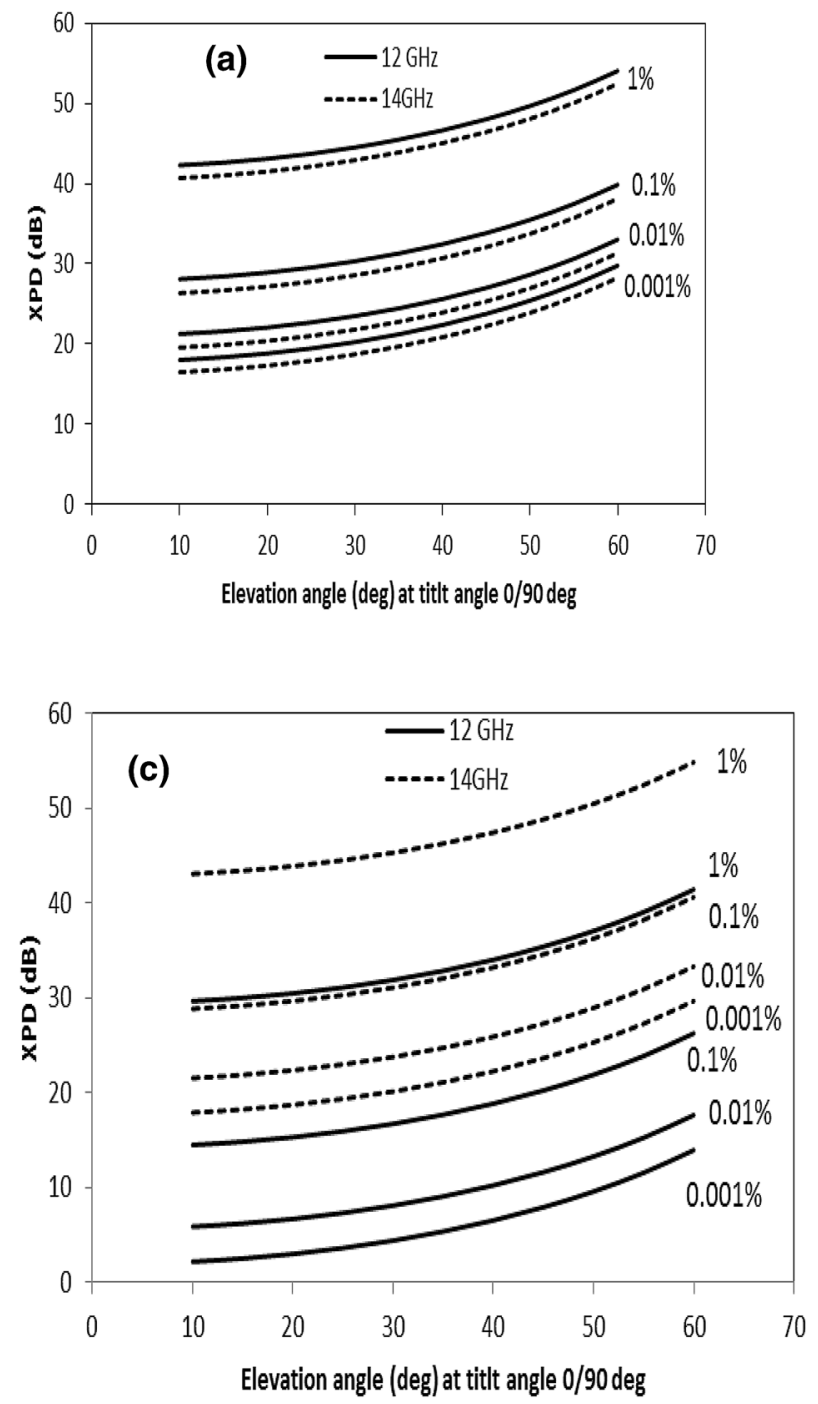

there is a marginal difference in XPD values between the uplink and downlink and at very low percentages of time as elevation angle progress positively, while significant difference exists between 1 and $0.1 \%$ of time in the values of XPD for both uplink and downlink. Even though high frequency of rainfall occurred in this zone, the raindrop size is small compared to the wavelength of the radio waves; hence, more loss caused by attenuation is expected at this frequency band to justify the scattering of raindrops due to the wavelength of the signals. The correlation between the uplink and the downlink frequency band shows that depolarization would increase if the wavelength of the radio waves decreases. Crosstalk will be better in downlink than in uplink in other locations (Fig. 5b-d). However, XPD values in the uplink frequency and at $0.001 \%$ of time are slightly above $15 \mathrm{~dB}$, hence considering a communication
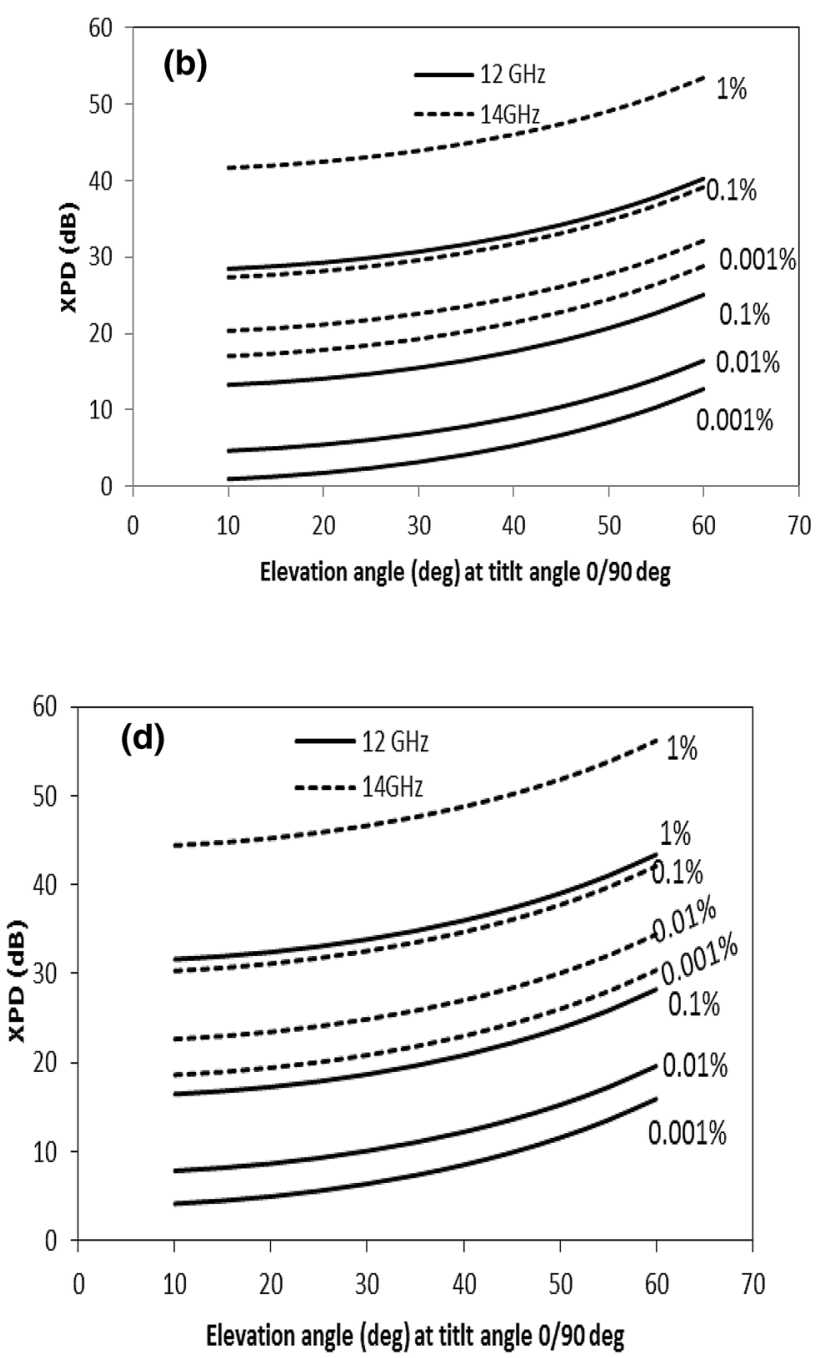

Fig. 5 Comparison of XPD with elevation angle and fixed polarization tilt angle of $0 / 90^{\circ}$ at Ku-band downlink and uplink frequencies for locations in a Port-Harcourt, b Nsukka, c Yola and d Sokoto 
system with a fade margin of $20 \mathrm{~dB}$, an increase in the fade margin may be required especially at low percentages of time and elevation angles to guarantee good system link reliability of the systems and quality signals transmission. The same trend could be observed in other locations although with different XPD values at both uplink and downlink frequency bands. Also, rainfall intensity in these locations is low compared with Port-Harcourt. Signal transmission at a low percentage of time is not encouraged as XPD is generally poor at $0.001 \%$ of time in Nsukka, Yola and Sokoto.

Figure 6 also presents XPD for fixed polarization tilt angle of $90^{\circ}$, for the specified locations in the Q/V frequency bands. XPD displayed a similar trend as in Fig. 5 but with different values. Based on this study, the degradation effect on radio signals during transmission will be
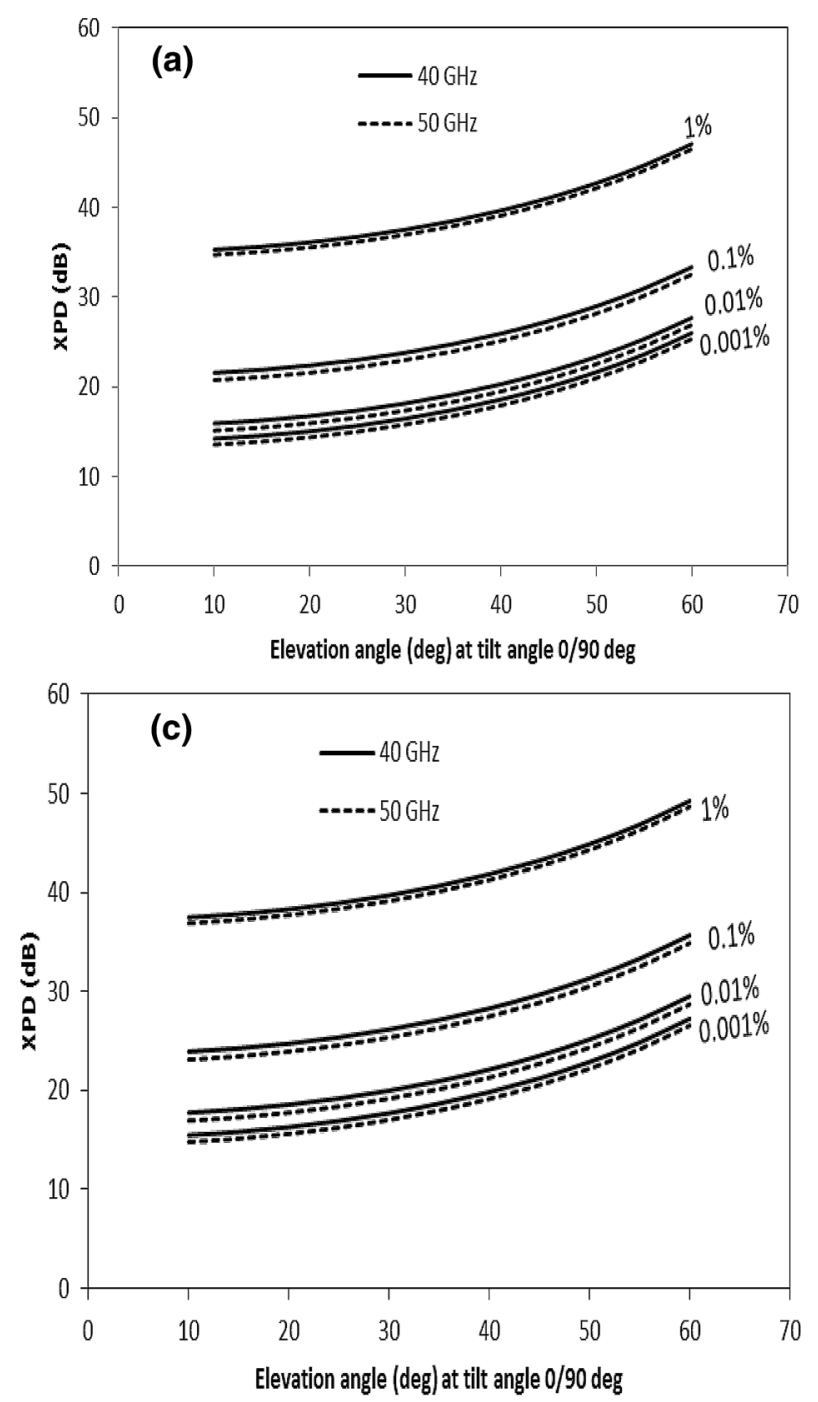

better in the Ku frequency bands than at $\mathrm{Q} / \mathrm{V}$ frequency bands irrespective of the elevation angle at a fixed polarization tilt angle of $90^{\circ}$.

\subsection{Effect of polarization tilt angle for circular polarization on XPD at $45^{\circ}$}

We also present the results for a fixed polarization tilt angle of $45^{\circ}$, for the specified locations. The comparison has been based on the typical results at Ku and Q/V downlink and uplink frequencies as presented in Figs. 7 and 8, respectively.

In Fig. 7, the same scenario occurs as in the case when the polarization tilt angle is as shown in Figs. 5 but with lower values of XPD. XPD values are better at downlink of Ku frequency band than at its uplink and keep on
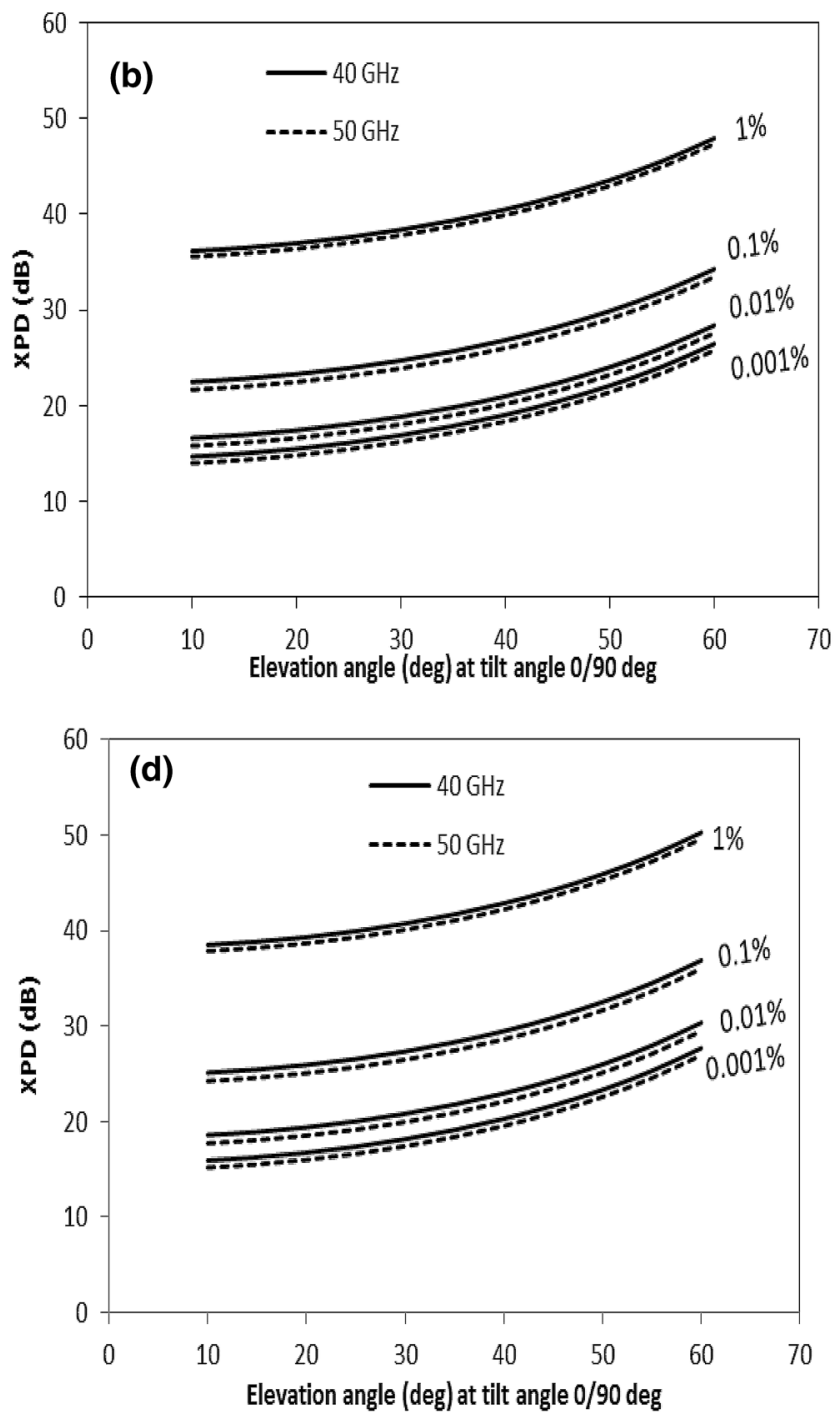

Fig. 6 Comparison of XPD with elevation angle and fixed polarization tilt angle of $0 / 90^{\circ}$ at Q/V-band downlink and uplink frequencies for locations in a Port-Harcourt, b Nsukka, c Yola and d Sokoto 
increasing as percentage of time and elevation angle increases. At Ku frequency band, depolarization-induced interference will be higher than in Fig. 5 because of lower values of XPD. For example, at Port-Harcourt with the worst scenario, the deviation in the XPD values is about $14 \mathrm{~dB}$ between a fixed polarization tilt angle of $45^{\circ}$ and that of $90^{\circ}$. There exists a significant difference in the values of XPD between 1 and $0.1 \%$ of time for both uplink and downlink for a fixed polarization tilt angle of $45^{\circ}$, and the values of XPD go toward zero values at $0.001 \%$ of time, especially at elevation angle is $10^{\circ}$.

Interference level will be higher in these locations, particularly between 0.001 and $0.01 \%$ of time. The fade margin of $20 \mathrm{~dB}$ may not sustain good quality radio wave propagation at these levels of availability without appropriate mitigation technique [21].

At the $\mathrm{Q}$ and $\mathrm{V}$ frequency bands, the results of the effects of polarization tilt angle of $45^{\circ}$ on the XPD as presented in Fig. 8 for the specified locations show that XPD displays comparable trend as in the Ka band, however, with different values. In these figures, the XPD attains highest values at an elevation angle of $60^{\circ}$ while it attains very poor values at low elevation angle and goes to zero value at a low percentage of time. At an elevation angle of $30^{\circ}$, $X P D$ values begin to increase sharply and steeping upward at each percentage of time in these locations with peak values at an elevation angle of $60^{\circ}$. Generally speaking, crosstalk would be higher in the uplink than in the downlink of both $Q$ and $V$ frequency bands. Transmitting signals between 1 and $0.1 \%$ of time will produce better signals at the receiver station than between 0.01 and $0.001 \%$ of time because of the level of unwanted signals that may be encountered in the orthogonal channels of a frequency reuse systems. There is a large difference in the values of XPD between 1 and $0.1 \%$ of time in both the uplink and downlink frequencies. Signal outage may often occur during signal transmission, especially at $0.001 \%$ of time and very low elevation angles. Radio signals would encounter
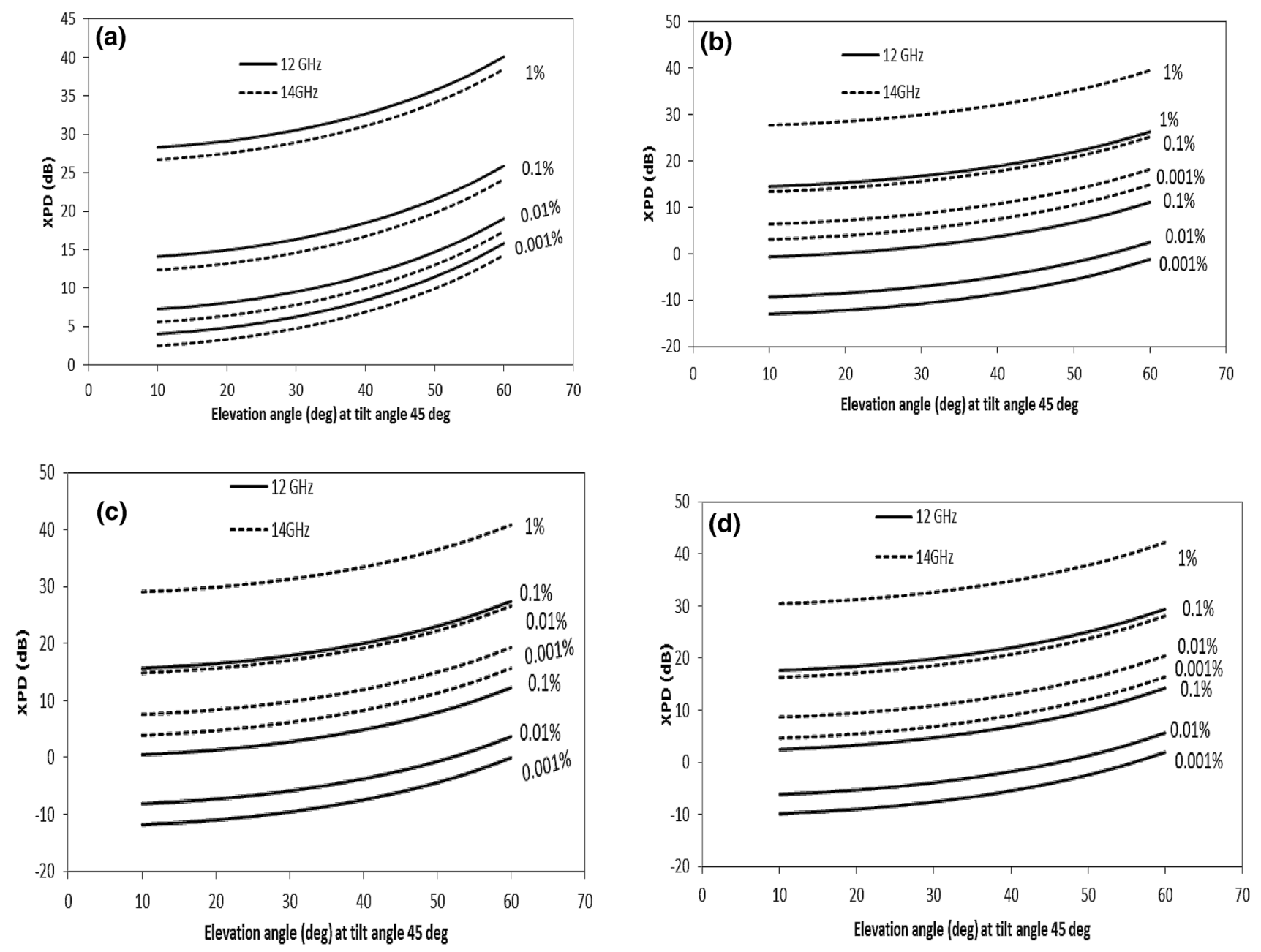

Fig. 7 Comparison of XPD with elevation angle and fixed polarization tilt angle of $45^{\circ}$ at Ku-band downlink and uplink frequencies for locations in a Port-Harcourt, b Nsukka, c Yola and d Sokoto 

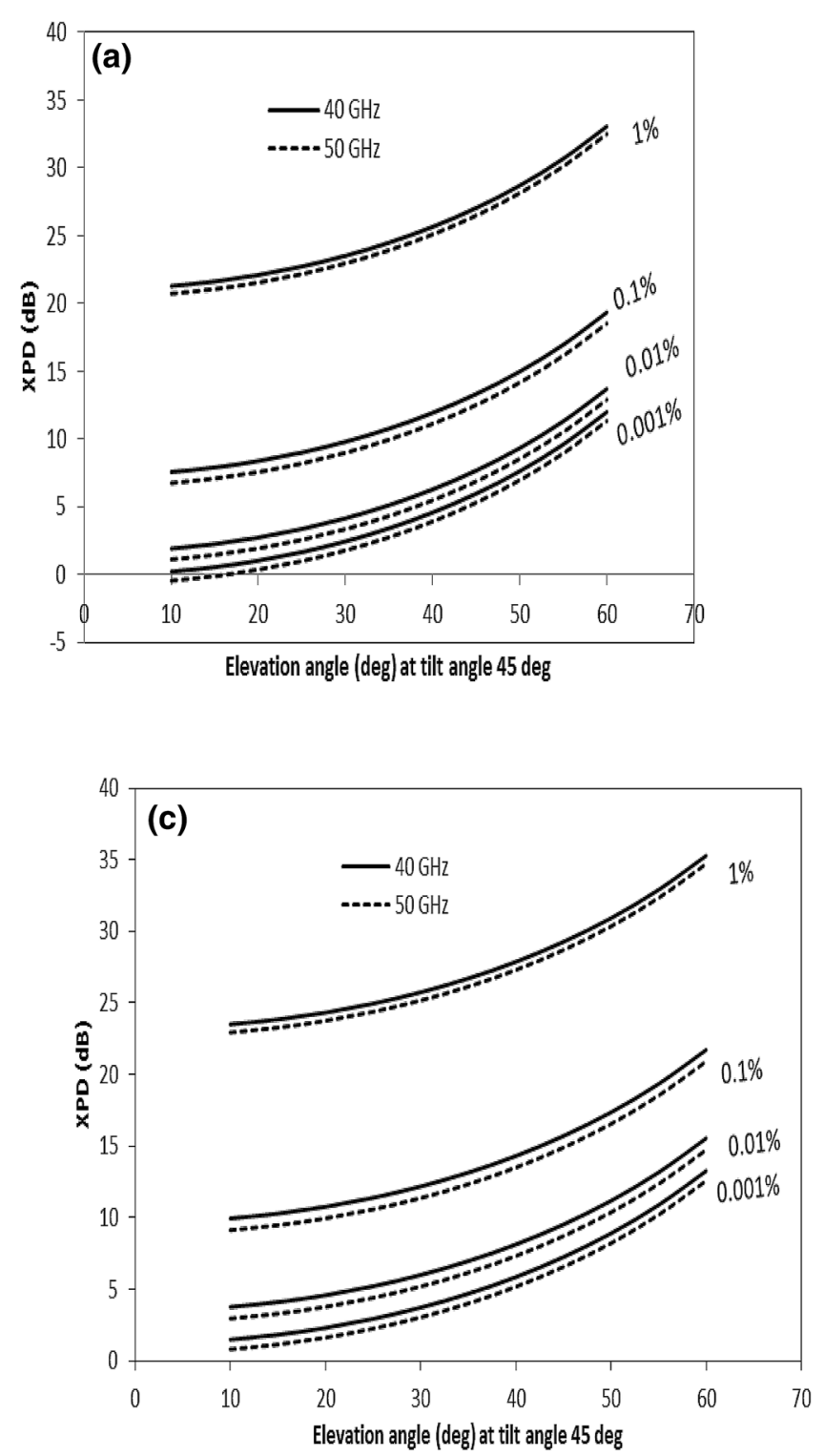
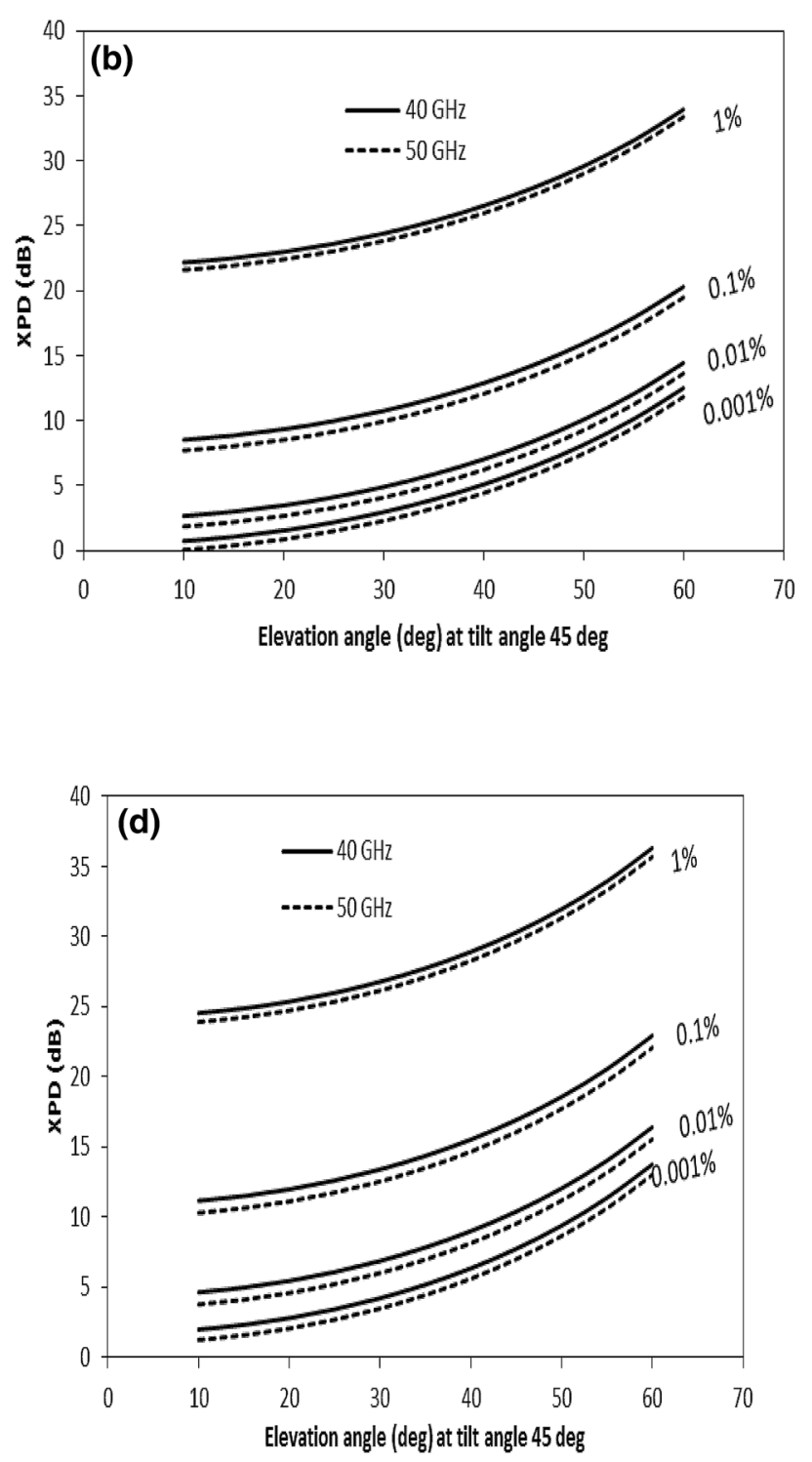

Fig. 8 Comparison of XPD with elevation angle and fixed polarization tilt angle of $45^{\circ}$ at Q/V-band downlink and uplink frequencies for locations in a Port-Harcourt, b Nsukka, c Yola and d Sokoto

higher level of crosstalk during propagation at an elevation angle of $10^{\circ}$ between 0.01 and $0.001 \%$ of time than in other percentages of time; hence, transmitting signals at $0.01 \%$ and $0.001 \%$ of time will require an increase in the fade margin $(\sim 20 \mathrm{~dB})$ of the communication systems and adoption of mitigation techniques for better quality of the output radio signals at receiving stations.

\section{Conclusion}

Assessing the level of degradation due to interference on dual-polarized communication systems for millimeter wave's band over some selected locations in Nigeria was estimated and reviewed. XPD and CPA are computed for both linear and circular polarizations over a varying propagation path at an elevation angle ranging from $10^{\circ}$ to $60^{\circ}$ and frequency range of $10-55 \mathrm{GHz}$ based on rain rate ranging from 5 to $210 \mathrm{~mm} / \mathrm{h}$ using the recent ITU model. In terms of the variation in XPD-induced interference with earth station frequency, XPD values degrade by $1 \mathrm{~dB}$ from 12 to $55 \mathrm{GHz}$. It is evident that the depolarization effect contributes better at low availability with higher value of XPD and its performance to system availability at the lowest exceedance probabilities. Port Harcourt, Nsukka, Yola and Sokoto experiences increased interference at receiver stations than other locations considered in this study, especially at Q/V band frequencies. Hence, a system 
like direct-to-home (DTH) service may require an increase in fade margin or other mitigation methods if link availability and the quality of service (QoS) are to be sustained. Also, deviation in the XPD values of about $15 \mathrm{~dB}$ could be encountered between a fixed polarization tilt angle of $45^{\circ}$ and that of $90^{\circ}$. It can therefore be concluded that radio signals would encounter higher level of crosstalk during propagation at an elevation angle of $10^{\circ}$ between 0.01 and $0.001 \%$ of time than in other percentages of time; hence, transmitting signals at $0.01 \%$ and $0.001 \%$ of time will require an increase in the fade margin $(\sim 20 \mathrm{~dB})$ of the communication systems and adoption of mitigation techniques for better quality of the output radio signals at receiving stations.9, 15].

Acknowledgements The authors wish to acknowledge the Centre for Atmospheric Research of NASRDA, Kogi State University, Anyigba, Nigeria for the TRODAN data used for this work.

\section{Compliance with ethical standards}

Conflict of interest The authors declare that they have no conflict of interest.

\section{References}

1. Panagopoulos AD, Arapoglou PDM, Cottis PG (2004) Satellite communications at $\mathrm{Ku}, \mathrm{Ka}$, and $\mathrm{V}$ bands: propagation impairments and mitigation techniques. IEEE Commun Surv Tutor 6:2-14

2. Ippolito LJ (2008) Satellite communications systems engineering: atmospheric effects, satellite link design and system performance, 1st edn. Wiley, Chicester, pp 6-8

3. Ojo JS, Ajewole MO, Sarkar SK (2008) Rain rate and rain attenuation prediction for satellite communication in Ku and Ka bands over Nigeria. Prog Electromagn Res B 5:207-223

4. Ajewole MO, Oguchi T (2002) Attenuation and depolarization of millimeter waves due to incoherent scattering in tropical rainfall. J Quant Spectrosc Radioact Transf 83:149-158

5. Oguchi T (1983) Electromagnetic wave propagation and scattering in rain and other hydrometers. Proc IEEE 17:1029-1078

6. Stutzman WL, Runyon DL (1984) The relationship of rain-induced cross-polarization discrimination to attenuation for 10-30 $\mathrm{GHz}$ earth-space radio links. IEEE Trans Antennas Propaga $32: 705-710$
7. Ojo JS (2012) Estimation of cross-polarization due to rain over some stations in Nigeria. Ann. Telecommun 67:241-245

8. Adetan O, Afullo TJ (2013) Computation of cross-polarization due to rain over durban. S Afr Int J Sci Eng Res 4:1169-1175

9. Karasuwa AS, Eastment JD, Otung IE (2016) Cross polarization discrimination-induced interference in dual polarized high capacity satellite communication systems. J Eng 2016(6):162-170

10. Durodola OM, Aminu I, Ojo JS, Ajewole MO (2018) Investigation of depolarization and cross polarization over Ku-band satellite links in a Guinea Savanna Location, Nigeria. Phys Sci Int J 17:1-9

11. Thurai M, Tan J (1996) Calculation of rain induced cross-polarization on line of sight systems at $38 \mathrm{GHz}$. IEEE, London, pp 1-8

12. Sen R, Geetha P, Uma S (2007) I estimation of cross-polarization due to rain over some stations in India. Indian J Radio Space Phys 30:159-164

13. Yussuff Al, Nor HH (2012) Rain attenuation modeling and mitigation in the tropics: brief review. Int J Electr Comput Eng 2:748-757

14. ITU-R P.618-12 (2015) Propagation data and prediction methods required for the design of Earth-space telecommunication systems. In: Recommendation, P series ITU-R. International Telecommunication Union, Geneva

15. Zubair M, Haider Z, Khan SA, Nasir J (2011) Atmospheric influences on satellite communications. J Electr Rev 87:261-264

16. Van de Kamp M (1999) Depolarization due to rain: XPD-CPA relation. Int J Satell Commun 9:285-301

17. Paraboni A, Martellucci A, Capsoni C, Riva CC (2011) The physical basis of atmospheric depolarization in slant path in the $\mathrm{V}$ band: theory, Italsat experiment and models. IEEE Trans Antenna Propag 59:4301-4314

18. Elfatih A, Elsheikh A, Suliman FM, Islam MR, Mohamed HH, Ahmad Fl, Elshaikh ZEO, Jalel C (2018) Air born dust particles effects on microwave propagation. In: Arid-area 7th international conference on computer and communication engineering. pp 8-15

19. Chu TS (1974) Rain induced cross polarization at centimeter and millimeter wave lengths. Bell Syst Tech J 53:1557-1579

20. ChuTS (1982) A semi-empirical formula for microwave depolarization versus rain attenuation on earth-space paths. IEEE Trans Commun 30:2550-2554

21. Sarma AD, Prasad MVSN (1999) Rain-induced cross-polarization at $\mathrm{cm}$ and $\mathrm{mm}$ wave lengths: a comparison of existing models. Indian J Radio Space Phys 28:159-164

Publisher's Note Springer Nature remains neutral with regard to jurisdictional claims in published maps and institutional affiliations. 